FETC Contract DE-AC26-99FT40569

\title{
ALTERNATE HIGH EFFICIENCY PARTICULATE AIR (HEPA) FILTRATION SYSTEM
}

\author{
Topical Report
}

Task B.1.2: Conceptual Design (rev. 2.0, 9/3/99)

Reporting Period Start Date: $\quad$ May 19, 1999

Reporting Period End Date: $\quad$ September 3, 1999

Leon Mir, Bruce Bishop, and Robert Goldsmith

September 3, 1999

FETC Contract DE-AC26-99FT40569

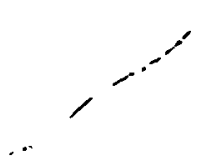

CeraMem Corporation

12 Clematis Avenue

Waltham, MA 02453

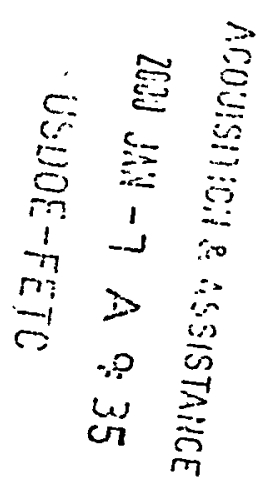




\section{DISCLAIMER}

"This report was prepared as an account of work sponsored by an agency of the United States Government. Neither the United States Government nor any agency thereof, nor any of their employees, makes any warranty, express or implied, or assumes any legal liability or responsibility for the accuracy, completeness, or usefulness of any information, apparatus, product, or process disclosed, or represents that its use would not infringe privately owned rights. Reference herein to any specific commercial product, process, or service by trade name, trademark, manufacturer, or otherwise does not necessarily constitute or imply its endorsement, recommendation, or favoring by the United States Government or any agency thereof. The views and opinions of authors expressed herein do not necessarily state or reflect those of the United States Government or any agency thereof." 


\section{DISCLAIMER}

Portions of this document may be illegible in electronic image products. Images are produced from the best available original document. 


\subsection{Overall Process Description:}

The following summary report outlines the initial Regenerable HEPA Filtration System (RHFS) conceptual design. Modifications to this design will be proposed as described in the Phase II follow-on funding proposal to be sent to DOE on September 3, 1999.

The RHFS removes submicron particles from a High Level Waste (HIW) tank venting air stream. The air is drawn from the top of the tank, through one of the filter sets (2 filters), by a constant volume vacuum pump. The suction rate of the vacuum pump is 500 ACFM. This corresponds to a flow rate from the tank vent of 450 ACFM when the filter is clean (pressure drop of 50" water) and a flow rate from the tank vent of 255 ACFM when the filter is dirty (pressure drop of 204" water).

While one of the filter sets is filtering the air stream, the other filter set is in a stand-by mode. The filters become partially plugged as particles filter out on the surface of the membrane during operation. When the pressure at the inlet to the vacuum pump drops to 7.5 psia, the dirty filter set will be isolated and the standby filter set will be connected to the tank. Plugging may occur every 4,000 to 8,000 hours.

The dirty filter set is regenerated by a three-step procedure (See. Table I for valve positions):

- Nitric acid (10\%) flows by gravity from an elevated tank into the feed side of the two filters being regenerated. Both the feed side and the downstream side of the filters are filled with acid. About 20 liters of acid are used per filter, for a total of 40 liters per filter set.

- After a set time, perhaps two hours, the acid is drained into the waste storage tank.

- The filter is filled completely with filtered process water from the product side. The water is displaced with air into the waste storage tank. This step is repeated three times.

- The annular space between the filter and the housing is flushed with water into the waste storage tank.

- The filter is dried by flowing dry instrument air from the product side, through the filter, into the headspace of the tank being vented or into the suction of the vacuum pump. If the entire wall thickness of the filter is filled with water, it will require about $7500 \mathrm{ft}^{3}$ of air to evaporate this water. This process will take less than one hour at a flow rate per filter of 12.5 CFM. This is about $2.5 \%$ of the vent rate.

- The acidic wastes, about 200 liters, are neutralized with sodium hydroxide and pumped into the tank being vented.

\subsection{Overall System Description:}

The full size system, if selected for fabrication, will be designed to meet the requirements

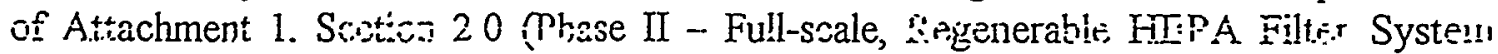
Design Requirements) of the Statement of Work. At this stage of the conceptual design, 
not all the requirements have been addressed. The requirements and CeraMem's comments are located in Appendix A. .

Figure 1 is a schematic of the process lines and principal instruments. The associated Table I displays the positions of the control valves during the phases of the operating cycle. The entire system is mounted on a 304 SS skid with overall dimensions of 6 feet long, 3 feet wide and 6 feet high. The layout of components on the slid requires a detailed engineering design and is properly a part of Phase II of this project.

\subsection{System Components:}

Components that contact the vent air will be, where available, $316 \mathrm{~L}$ stainless steel and Viton $^{\mathrm{TM}}$ fluorocarbon elastomer. We have requested of Mr. Duane Adamson that he obtain suggestions from the responsible engineering groups-at the SRTC for our choice of components and materials. Our ultimate choice will be guided by their preferences, particularly their experience with radiation compatibility.

1. Ceramic Filters: Four, membrane-coated, silicón carbide filters with a nominal area of 50 square feet per filter. The membrane coating is composed of glass-frit-bonded zirconium silicate. In the full-scale system, end rings will not be bonded onto the ends of the filter elements. Inorganic cement similar in composition to the membrane, will replace the epoxy used in Phase I to plug the filter channels: It is anticipated that the substrate and membrane will be compatible with the chemical environment and have sufficiently long lifetime to meet the system requirements.

\section{Filter housings: $316 \mathrm{~L}$ stainless steel}

3. Vacuum pump- - Roots or equal rated at 500 ACFM suction with a 15 HP motor. The $15 \mathrm{HP}$ is needed when the pressure drop through the filters reaches 204 " of water.

\section{Controller -- Allen-Bradley SLC 500 PLC}

5. Control system voltage - $120 \mathrm{VAC} 50 / 60 \mathrm{~Hz}$

6. Valves - all automated valves have an auto-manual selector switch for manual operation as well as operi-close indicator lights on the control panel. The valve bodies are of $316 \mathrm{~L}$ stainlesș.steel and the seals are of Viton ${ }^{\top M}$.

7. Differential pressure transmitters - Rosemount series $3051 \mathrm{CD}$

8. Pressure transmitters - Rosemount series 3051CG

9. Level switches - Great Lakes Instruments model 14L

10. $\mathrm{pH}$ transinitter and senser Thomton seies $200 \mathrm{pH}$ 
11. Recycle pump on waste tank - Goulds G\&L SST 1/2 HP TEFC

12. Nitric acid tank (316LSS) - working volume of 80 liters.

13. Caustic tank (316LSS) - working volume of 80 liters.

14. Waste tank (316LSS) - working volume of 200 liters. There is a 0.2 micron (PTFE) vent filter ( 1 square foot filter area) on top of this tank.

15. Caustic pump - Pulsafeeder

16. Vacuum piping - 316LSS 4 inch

17. Liquid piping - 316LSS $1 / 4$ inch

18. Water Filters - polypropylene

\subsection{Operational Procedures:}

\subsection{Preparation of Chemicals}

The nitric acid cleaning solution will be prepared manually by mixing concentrated nitric acid and process water in the supplied tank. In view of the small volumes needed and the infrequency of preparation, an automated system is not warranted. The same approach will be taken for the preparation of the caustic solution needed for neutralization of the acid cleaning solution. Normal safety procedures including operator training, protective garments and hazardous spill kits will have to be observed.

\subsection{Switching of Filter Sets}

When a filter set approaches it maximum differential pressure an aiarm will alert the operators to switch to the stand-by filter set and to initiate the cleaning of the dirty filter set. The actual cleaning procedure, due to its complexity, will be carried out automatically by the PLC.

\subsection{Change Out of-Filters}

Should a filter set require changing, the change will be made after the filter has been cleaned and dried. The entire filter assembly, filter and housing, will be removed and capped. A new filter assembly will be installed in the system. The spent filter assembly will be disposed of according to SRS's procedure for handling materials corresponding to the contamination level of the filter. Replacement of the filters in the old housing is not envisioned at this time due to the anticipated long life of the filters and the relatively low size and cost of the housing. In addition, this will considerably limit the amount of time personnel will be exposed to radiation from the spent assembly.

\section{$\Xi 0$ Phase II Míanágement}


In Phase II, CeraMem will propose to work with a selected lead engineering company to design the full-scale system. After reviewing the design with SRP engineering groups, it will be decided if additional alternative bids will be necessary from other engineering companies based on the required level of expertise nuclear wastestream process equipment and anticipated cost. Final bids will be reviewed with the responsible SRP engineering groups for conformance and the vendor with the lowest cost conforming bid will be selected to build the system.

In parallel, CeraMem will fabricate and have tested a small number of prototype and full size filter elements both at CeraMem and SRS. This work will demonstrate the effectiveness of the full size filters for retention, pressure drop, and regenerability.

The full-scale system will be produced and tested prior to shipment to SRS. Full size filter assemblies will be fabricated and tested at CeraMem for pressure drop and retention using in-house quality control test procedures. The criteria for filter selection will be developed based on the performance of similar filters tested at SRS. The filter assemblies will be sent to the system fabricator and installed in the process system. Mechanical and electrical testing of the system using air and water will be performed for integrity and execution of the operating cycle at the vendor's facility. CeraMem and SRP personnel will be present to witness the tests. Based on the results of this test, a complete Operating and Maintenance Manual will be written by CeraMem.

After the system is shipped to SRS, it will be tested and then installed on a tank vent system. Initial testing will include at least a standard DOP test for retention by the entire system. Additional testing may include all or part of the initial integrity and operation testing performed at the system vendor's site. After the system has been checked by SRS personnel, it will be installed on the vent system of the HLW tank.

It is anticipated that the system will be delivered to SRS within 30 weeks of the start of Phase IIB.

6.0 : :osts:

\subsection{System Cost}

The system cost is estimated to be $\$ 95,000$ based on the following:

Filter and Housing Cost: $\$ 38,000$ (CeraMem estimate based on crossflow-membranefilter manufacture.)

System Cóst:

$\$ 57,000$ (To industrial standards, not to SRS standards. Quote supplied by Enpure, Newton, MA)

\subsection{Operating Costs}

The operating costs are based on 24-hour per day, 365 days per year operation. Maintenance costs are based on CeraMem personnel's experience in industrial filtration system upkeep. Total operating costs are estimated at this time to be $\$ 4,860$ per year.

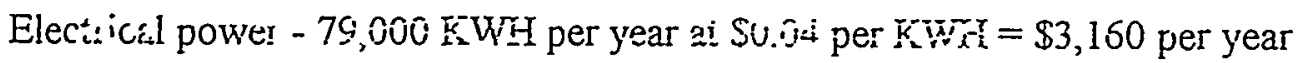


System Maintenance - $2 \%$ of $\$ 85,000=\$ 1,700$ per year 


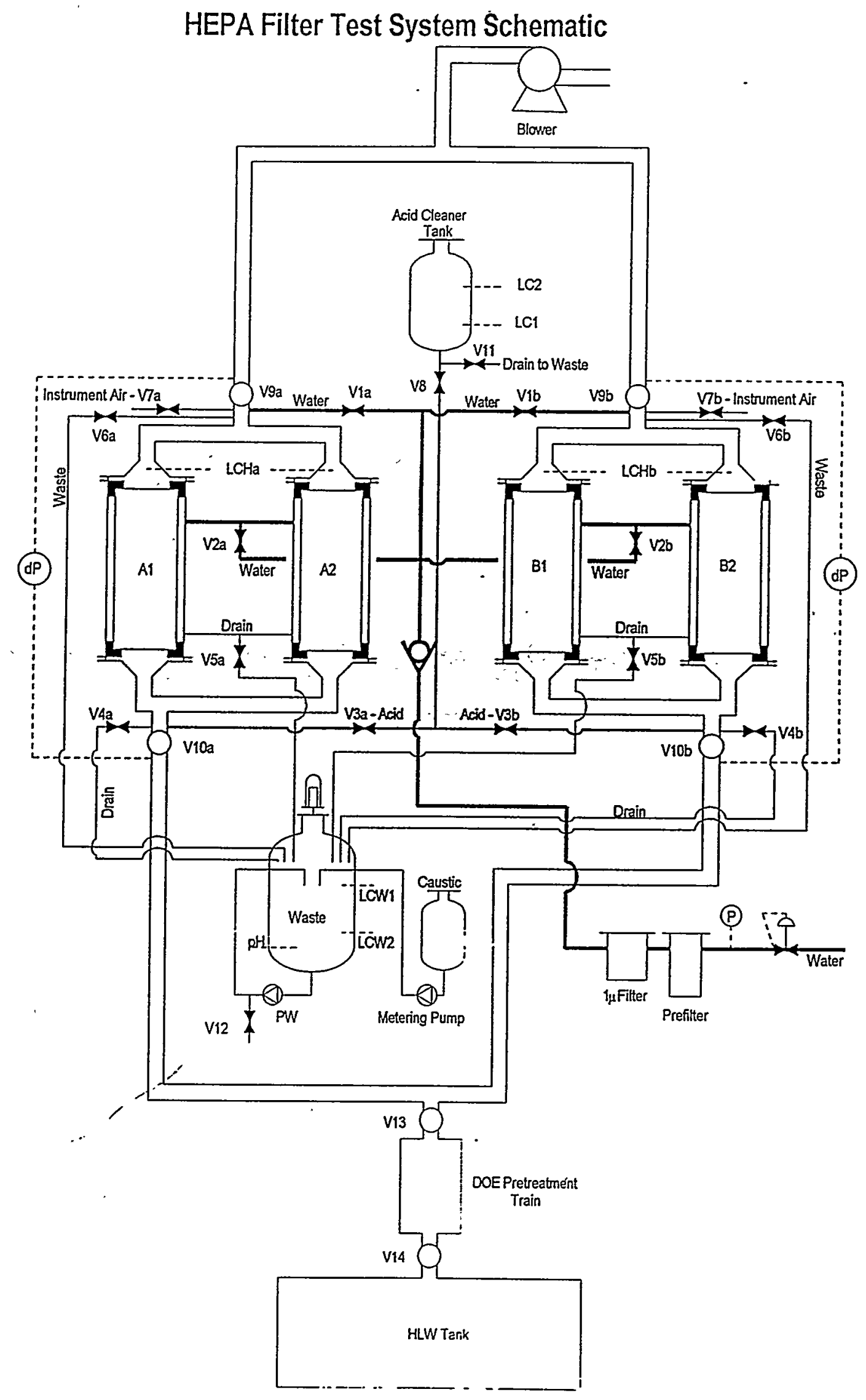




\section{Key for HEPA Filter Test System Schematic}

The following key lists the components of the HEPA filter test system schematic. The system uses four CeraMem filter modules (A1, A2, B1 and B2) which are divided into two parallel assemblies.

\section{Valves:}

$\mathrm{Vla} / \mathrm{VIb}$ : Filter flushing water line valves for housing filter assemblies $\mathrm{A}$ and $\mathrm{B}$.

V2a/V2b: Housing annulus flushing water line valves for housing filter assemblies $A$ and $B$.

$\mathrm{V} 3 \mathrm{a} / \mathrm{V} 3 \mathrm{~b}$ : Acid cleaning line valves for housing filter assemblies $\mathrm{A}$ and $\mathrm{B}$.

$\mathrm{V} 4 \mathrm{a} / \mathrm{V} 4 \mathrm{~b}$ : Upstream housing drain line valves for housing filter assemblies $\mathrm{A}$ and $\mathrm{B}$.

V5a/V5b: Housing permeate drain line valves for housing filter assemblies $A$ and $B$.

V6a/V6b: Downstream housing drain line valves for housing filter assemblies $A$ and $B$.

$\mathrm{V7a} / \mathrm{V7b}$ : Instrument air line valves for housing filter assemblies $\mathrm{A}$ and $\mathrm{B}$.

V8: $\quad$ Acid cleaning tank valve.

V9a/V9b: Downstream housing assembly isolation valve for assemblies $A$ and $B$.

V10a/V10b: Upstream housing assembly isolation for housing filter assemblies A and B.

V11: Acid cleaning tank drain valve.

V12: Waste neutralization tank drain valve.

V13: Downstream DOE pretreatment train isolation valve.

V14: Upstream DOE pretreatment train isolation valve/HLW tank isolation valve.

\section{Instrumentation:}

LCl: Cleaning acid low-level controller.

LC2: Cleaning acid high-level controller.

LCW1: Waste tank high-level controller.

LCW2: Waste tank low-level controller.

$\mathrm{dP}$ : Pressure drop gauges for housing filter assemblies $\mathrm{A}$ and $\mathrm{B}$.

$\mathrm{P}$ : Water feed pressure gauge.

$\mathrm{pH}$ : Waste tank $\mathrm{pH}$ controller.

PW: Mixing/Drainage pump for waste.

Lines:

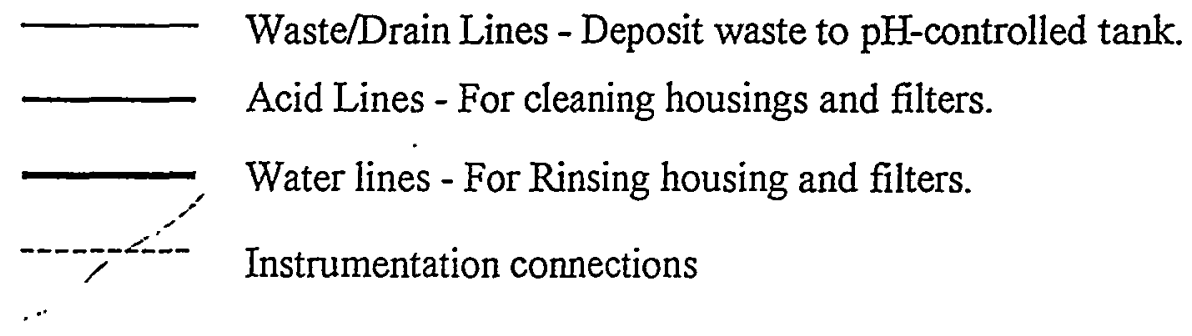




\begin{tabular}{|c|c|c|c|c|c|c|c|c|c|c|c|c|c|c|c|c|c|c|}
\hline & & \multicolumn{14}{|c|}{ Valve Positions } & \multirow[b]{2}{*}{ Control } & \multicolumn{2}{|c|}{ Pumps } \\
\hline & Step & V1A & TV2A & V3A & TVAA & V5A & IV6A & IVA & TV8 & IV9A & IV98 & IV10A & V10B & J11 & V12 & & PW & Metering \\
\hline 1 & Fill with acid & & & 0 & & & 10 & & 0 & & 0 & & 0 & & & Volume in acid tank & & \\
\hline 2 & Soak in acid & & & & & & 0 & & & & 10 & & 0 & & & 2 hours & & \\
\hline 3 & Drair acid & & & & 0 & 10 & 10 & & & & To & & 0 & & & 0.5 hours & & \\
\hline 4 & Fill vith water & 0 & & $:$ & To & 0 & & & & & 10 & & 0 & & & To level LCH & & \\
\hline 5 & Drair: water & & & & 0 & 10 & & 0 & & & 10 & & 0 & & & 0.1 hour & & \\
\hline 6 & Fill with water & 0 & & & To & o & & & & & 10 & & 0 & & & To level LCH & & \\
\hline 7 & Drain water & & & 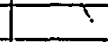 & o & 0 & & 0 & & & 0 & & 0 & & & 0.1 hour & & \\
\hline 8 & Fill with water & 0 & & & 0 & 0 & & & & & 10 & & 0 & & & To level LCH & & \\
\hline 9 & Drair: water & & & & 0 & 0 & & 0 & & & 0 & & 10 & & & 0.1 hour & & \\
\hline 10 & Flusti annulus & & To & & & 0 & & & & & 10 & & 0 & & & 0.05 hour & & \\
\hline 11 & Dry filter & & & & & & & 0 & & & To & to & To & & & 1 psig 0.5 hour & & \\
\hline 12 & Isolate clean filter & & & & & & & & & & 10 & & To & & & & & \\
\hline 13 & Neutralize waste & & & & & & & & & & 0 & & 10 & & & $\mathrm{pH}$ above 8 & on & on \\
\hline 14 & Drain waste & & & & & & & & & & 10 & & 0 & & 0 & & & off \\
\hline & Normal position & & & & & & & & & 0 & & 0 & & & & & off & \\
\hline & & & & & & & & & & & $\therefore$ & & & & & & & \\
\hline & & & & & & & & & & & & & & & & $=$ & & \\
\hline & Notes: & & & & & & & & & & & & & & & & & \\
\hline & Oper valves are ir & dicate & pyo & & & & $\perp$ & & & & $\therefore$ & & & & & & & \\
\hline & Vaiviss not shown & as ope & are clo & & & & & & & & & & & & & & & \\
\hline & Valves 13 and 14 & not sh & $\mathrm{vn}$ in th & chart, a & re oper & in all ce & & & & & & & & & & & & \\
\hline & These regeneratio & instr & ions d & cribe the & cleani & $\mathrm{g}$ of as & mbly $A$ & while a & emb & is $\ln$ & eration. & & & & & & & \\
\hline
\end{tabular}

- ' 
Appendix A to Conceptual Design Report Revision 2.0 Dated September 3, 1999

Comparison of Phase II - Full-scale, Regenerable, HEPA Filter System Design Requirements to Phase I Conceptual Design

2.1 The full-scale, regenerable HEPA filter system (RHFS) shall be designed for use on existing SRS HLW tanks. The system will replace the existing outdoor HLW tank ventilation system (See Drawing 2). The HLW tanks are outside in a non-controlled environment.

The system described in the Conceptual Design Report is designed to industrial filtration system standards. Changes will be required to make it conform to DOE requirements for outdoor operation on HLW tanks.

2.2 The system shall be designed and fabricated for use in a radioactive environment. The filter shall be capable of operating in radiation fields of $250 \mathrm{mR} /$ hour (milli-Roentgen per hour) of gamma radiation up to an integrated exposure of $10^{6} \mathrm{R}$

Radiation exposure has not yet been considered in the system design.

2.3 The full-scale system shall be designed for a nominal flow rate of 500 ACFM.

The conceptual system design meets this criterion.

2.4 The target volume of the HEPA filter enclosure should not exceed $125 \mathrm{ft}^{3}$. Minimizing the footprint of the system is desirable.

The conceptual system design meets this criterion.

2.5 A vacuum pump (or other air motive device) shall be sized for 500 ACFM airflow at 0 -

115 degrees $\mathrm{F}$, and at the pressure required for specific filter element operating conditions. The maximum vacuum on the suction side of the filter is $15 \mathrm{~m} \mathrm{Hg}$. Lower filter $\mathrm{dP}$ (differential pressure) is desirable, but high filter $\mathrm{dP}$ (as long as it is less than 15" $\mathrm{Hg}$ ) is acceptable. No moving parts are desired in the air stream between the HIW tank and the filter element.

The vacuum pump is capable of operation at these conditions but other system operations have not been addressed for performance at low temperature.

2.6 The vacuum pump shall be remote from the housing. All the SRS HLW tank ventilation system piping, ductwork, blower, filter housing, and filters will be replaced with a completely new system. (See Drawing 2).

CeraMem envisions the use of the same pretreatment train to eliminate liquid carry-over to the filters that is used on present disposable HEPA filtration systems. All other equipment will be replaced.

2.7 The filter housing shall be designed with an in-situ regeneration system that will restore the airflow across the filter to initial flow and ip affer a cleaning cycle. The contractc: shall provide all equipmeit necessary for cleaning (pumps, tanks, nozzles, etc.). Iŕa 
regenerating solution is used, the filter housing shall also have a drain system to collect spent wash solution. The RHFS regenerating solution shall meet the requirements for compatibility with Savannah.River's high level waster tanks and their contents as specified in Appendix A.

The conceptual system design meets this criterion.

2.8 The RHFS shall have an expected life of 15 years of continuous service.

The RHFS including the filters is being designed so as to meet this criterion.

2.9 The filter housing shall have a vacuum break between the pump and housing to prevent damage due to high vacuum.

The housing design utilized by CeraMem does not require such a vacuum break.

2.10 The filter housing shall be designed allow replacement of failed filter elements in such a manner that personnel are minimally exposed to contaminated equipment.

Direct replacement of individual filters will minimize expose time of personnel to contaminated equipment.

2.11 Design operating conditions are similar to those at the HFTA detailed above. Actual particulate composition, concentration, and size distribution in the HLW Tank ventilation system are highly variable and not defined.

Testing will be required to ensure that RHFS successfully operates on actual HLW tank vent air stream.

2.12 In the design and manufacture of the full-scale RHFS the supplier should follow standard quality assurance procedures.

Applicable quality assurance standards to be determined in consultation with SRS personnel.

2.13 Minimizing the volume of regenerating solution needed is required.

Cleaning solution volume requirements to be determined by testing at SRS. System dead volume to be minimized in detailed design task so as to minimize utilization of cleaning solution.

2.14 The vacuum on the HLW tank shall be approximately 1 "wc.

Vacuum break may be required between filtration system and HLW tank in order to maintain I" wc pressure in tank.

2.15 The RHFS shall be capable of operating in a highly caustic environment, with the potential for a $\mathrm{pH} 14$ salt solution to contact the internal surfaces of the system.

The conceptual system design meets this criterion. 
2.16 The RHFS shall be capable of operating in high humidity (up to 100\%) with the condensing solution potentially contacting the filter. The system shall also be capable of operating in a dry environment with salt and sludge particles impacting the filter surface. See Tables 1 and 2 for typical concentrations of SRS salt and sludge.

The conceptual system design including the liquid knockout pretreatment equipment is capable of operating with high and low humidity gas streams. If condensed liquids contact the filter, high pressure drop conditions will develop due to liquid in the membrane pores. However, the filter will be regenerable to proper operation after such upset conditions.

2.17 The full-scale HEPA filter system shall be capable of operating at ambient temperatures ranging from $0-115$ degrees $F$.

This design condition has not been considered in the conceptual system design. 


\section{ALTERNATE HIGH EFFICIENCY PARTICULATE AIR (HEPA) FLLTRATION} SYSTEM

\section{Topical Report}

Reporting Period Start Date: May 3, 1999

Reporting Period End Date: September 3, 1999

Leon Mir, Bruce Bishop, and Robert Goldsmith

September 3, 1999 .

DE-AC26-99FT40569

\section{CeraMem Corporation}

12 Clematis Avenue

Waltham, Már j̇i553

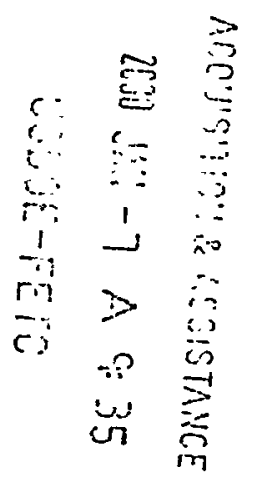




\section{DISCLAIMER}

"This report was prepared as an account of work sponsored by an agency of the United States Government. Neither the United States Government nor any agency thereof, nor any of their employees, makes any warranty, express or implied, or assumes an legal liability or responsibility for the accuracy, completeness, or usefulness of any information, apparatus, product, or process disclosed, or represents that its use would not infringe privately owned rights. Reference herein to any specific commercial product, process, or service by trade name, trademark, manufacturer, or otherwise does not necessarily constitute or imply its endorsement, recommendation, or favoring by the United States Government or any agency thereof. The views and opinions of authors expressed herein do not necessarily state or reflect those of the United States Government or any agency thereof." 


\subsection{Introduction:}

This report summarizes CeraMem's activities in the development of a regenerable ceramic filter to replace currently used disposable HEPA filters on the vents of tanks containing high level radioactive wastes.

CeraMem supplied the following items under the terms of the contract:

1.1 A stainless steel filter housing.

1.2 Two sets of ceramic filters with suggestions for their operation and cleaning 1.3 A Conceptual Design for a full scale filtration system

Throughout the evaliation period CeraMem was in touch with Mr. Duane Adamson regarding filter performance and other exchanges of information.

Based on the excellent results of this test work CeraMem is confident of being able to design and supply full-scale ceramic filtration systems to replace the HEPA filters currently in use.

\subsection{Chronology of Principal Events:}

2.1 The Project Kick Off Meeting was held at CeraMem on May 19, 1999. The minutes of this meeting are attached as Appendix 1 :

2.2 The stainless steel housing was sent to Mr. Adamson on May 27, 1999.

2.3 The first two filter elements were sent on June 18, 1999 . These filters were only used to fit up the system.

2.4 Suggestions for testing and cleaning the filters were sent Mr. Adamson on June 15, 1999.(Appendix 7).

2.5 The second set of filter elements was sent on July 8, 1999. These filters were used for the filtration and regeneration studies. A description of these filters in given in Appendix 2.

2.6 The Conceptual Design Report was sent on June 23, 1999. This report is attacheri as Appendix 3.

2.7 Comments on the Conceptual Design Report were received from FETC on August 27,1999. These are given in Appendix 4.

2.8 Monthly Progress Reports were sent on June 29, July 21, and August 20, 1999

In addition to these major events the following communications were held with $\mathrm{Mr}$.

Duane Ädamson:

2.9 Instructions for assembly of the filter and housing were faxed on June 14, 1999.(Appendix 5)

2.10 Suggestions for cleaning the filters were sent by e-mail on May 27, 1999. (Appendix 6).

2.11 Telephone conversations were held between Mr. Duane Adamson and Mr. Leon Mir on July 21, August 11 and August 16 regarding filter performance and design concents for a sidl scale system. The topics are wiscussed below. 
During the course of the program ad hoc conversations took place between Mr. Duane Adamson, Mr. William Haslebacher and CeraMem on various aspect of the program.

\subsection{Results of Filter Testing:}

Based on the conversations CeraMem has had with Mr. Adamson it appears that the filters supplied have been meeting the goals of the program:

3.1 The DOP retention of the filters has exceeded the $99.97 \%$ target level and is in range off $99.99 \%$.

3.2 It has been possible to regenerate the filters with nitric acid after they had been plugged with sludge simulant and South Carolina Road Dust. Back flushing with nitric acid is more effective than simply soaking in nitric acid.

The following aspects of filter performance should be improved however:

3.3 The filters, when clean, have a pressure drop of about 100 inches of water at the face velocity of 10 feet per minute. A lower pressure drop is desirable. CeraMem is in the process of fabricating test filters that should have a substantially lower pressure drop, without sacrifice of particle retention. efficiency.

3.4 Under the accelerated testing conditions, characterized by a large amount of liquid carry over from the sludge tank, the filters become wetted out and liquid appears on the downstream side. CeraMem agrees with Mr. Adamson's suggestion that a liquid disengagement section should be placed ahead of the filters. While such a disengagement section could be incorporated in the fullscale system design, CeraMem's approach in Phase II, if funded, will be to use the pretreatment equipment train located on present DOE HLW tanks.

4.0 Conceptual Design of Full Scale Filtration System:

Tie preliminary design has been revised in light of the comments received from FETC.

The modified design in attarhed as Appendix 8. 


\section{APPENDIX 1}


MEMORANDUM

To: Robert L. Goldsmith

From: Leon Mir

Subject: Project Kickoff Meeting - Contract No. DE-AC26-99FT4069

Date: May 19, 1999

Copy: William Haslebacher

File:

Duane Adamson

Richard Higgins

\subsection{Agenda:}

The agenda of the meeting was drawn up by CeraMem and included the following areas which were discussed:

- Introduction to CeraMem capabilities and activities - Robert Goldsmith

- Review of Program Plan - Leon Mir

- Design and preparation of test filters - Richard Higgins

- Regeneration Methods

- ijesign of full scale regenerable HEPA system

- Schedule

- Discussion

\subsection{Design and Preparation of Filters;}

Because of the limited scope of this project, filter performance will not be optimized. CeraMem will make a series of filters with different combinations of particle retention and pressure drop. The filter coming closest to meeting the program objectives will be submitted for testing.

Duane Adamson said that priority should be given to high particle retention but that in some applications a low pressure drop is needed so that existing duct work need not be replaced.

The silicon carbide substrate and the zircon based membranes are likely compatible with the radiation levels to which the filters are to be exposed. The epoxy used to bond the stainless steel to the filter may not be compatible. In the fill scale elements a different bonding method may be used. Rich Higgins will find literature citation on the ist:iation !esistance of the filter s materials. Duane 
Adamson is considering testing the radiation resistance by exposing the filters to a high level source.

\subsection{Regeneration Methods:}

It is not possible to get samples of simulated sludge to CeraMem for evaluation of regeneration methods but the road dust will be supplied.

Duane Adamson felt that the combination of air back pulsing and periodic soaking in nitric acid was complex and he would prefer a regeneration method that did not use air back pulsing.

The following aspects of the nitric acid regeneration method were agreed to:

- After the nitric acid soak the acid will be drained into a tank.

- The filter will be flushed with water, followed by caustic, into the same tank.

- The neutralized solution will be drained or pumped back into the tank.

- We need to drain the annular space between the filter and housing. For the Phase I prototypes Duane Adamson may modify our CeraMem housings to accomplish this.

William Haslebacher will provide CeraMem with the actual filtration area of the currently used HEPA filters so that CeraMem can estimate the regeneration frequency of its lower area filters. This is needed to calculate the volume of waste that is likely to be generated.

\subsection{Conceptual Full Scale Regenerable HEPA System:}

The flow capacity of 500 ACFM refers to the outlet of the vacuum pump operating with clean filter. Modest reductions in flow are allowed as the filter plugs.

The venting flow rate can be reduced to zero during filter regeneration provided that this process does not take more than a few hours.

Duane Adamson would prefer two parallel filters, each capable of filtering 500 ACFM.

For the purposes of the conceptual design CeraMem shouid consider that the demister, condenser and preheater will remain on the system.

Leon Mir will send Duane Adamson a number of questions about the equipment and design standards for the Exll Scale System.

Phase II call's for qualification testing of the full scale system before it is shipped. If the testing were done at CeraMem it would require the construction of a testing facility for one time use. William Haslebacher will investigate the feasibility of doing the testing at the UNDERC.

\subsection{Schedule:}

The schedule as presented was basically satisfactory. CeraMem should however try to deliver the filters within a month of this meeting. All aspects of the Phase I program need to be completed so as to allow Phase II funding to be committed to by October 1, 1999. 
CeraMem needs to send to William Haslebacher the Milestone Schedule Plan and the Cost Plan by the end of May.

CeraMem needs to send to William Haslebacher the updated Cost Proposal for Phase II by the end of August. 
APPENDIX 2

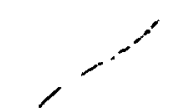




\section{Product Specification for Laboratory-Scale FETC HEPA Filters}

General Description

Honeycomb-based ceramic membrane filter with HEPA performance

Physical Characteristics

Overall Element Dimensions: $\quad 1.28$ " diameter (end ring) x 13.1" long

Ceramic Component Dimensions: 1.06 " diameter $x$ 12.0" long

Filter Configuration:

Flow-through, dead-ended filter

Number of Active Inlet Channels: $\quad 30$

Channel Opening Size: $\quad 0.066^{\prime \prime}$

Channel Wall Thickness: $\quad 0.03^{\prime \prime}$

Channel Plug Depth: $\quad 0.12$ "

Inactive Channel Sides: $\quad 16$ (next to skin around circumference)

Filtration Surface Area: $\quad 0.56 \mathrm{ft}^{2}$

Materials of Construction

Monolith Membrane Support:

Membrane Coating:

End Ring Adhesive and Plugs:

End Rings:

Silicon carbide

Glass-frit-bonded zirconium silicate and alumina

Zirconium-silicate-filled food-grade epoxy

$316 \mathrm{~L}$ stainless steel 
APPENDLX 3

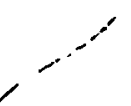

.. 


\title{
ALTERNATIVE HIGH EFFICIENCY PARTICULATE FILTRATION SYSTEM
}

Task B.1.2: Conceptual Design (rev. 1.0, 6/23/99)

Reporting period: May 19, 1999 - June 23, 1999

FETC Contract DE-AC26-99FT40569

\author{
Leon Mir \\ CeraMem Corporation \\ 12 Clematis Avenue \\ Waltham, MA 01778
}

June 23, 1999 


\section{DISCLAIMER}

"This report was prepared as an account of work sponsored by an agency of the United States Government. Neither the United States Government nor any agency thereof, nor any of their employees, makes any warranty, express or implied, or assumes any legal liability or responsibility for the accuracy, completeness, or usefulness of any information, apparatus, product, or process disclosed, or represents that its use would not infringe privately owned rights. Reference herein to any specific commercial product, process, or service by trade name, trademark, manufacturer, or otherwise does not necessarily constitute or imply its endorsement; recommendation, or favoring by the United States Government or any agency thereof. The views and opinions of authors expressed herein do not necessarily state or reflect those of the United States Government or any agency thereof." 


\subsection{Overall Process Description:}

The filtration system removes submicron particles from a tank venting air stream. The air is drawn from the top of the tank, through one of the filter sets ( 2 filters), by a constant volume vacuum pump. The discharge rate of the vacuum pump to the atmosphere is 500 SCFM when the filters are clean.

While one of the filte: sets is filtering the air siream, the other filter set is in a stand by mode.

The filters become partially plugged by the particles that they filter out. When the discharge rate of the vacuum pump drops to 400 SCFM the dirty filter set is isolated and the stand by filter set is connected to the tank and the vacuum pump. Plugging may occur every 4000 to 8000 hours.

- The dirty filter set is regenerated by a three step procedure:

- Nitric acid (10\%) flows by gravity from an elevated tank into the feed side of the two filters being regenerated. Both the feed side and the downstream side of the filters are filled with acid. About 20 liters of acid are used per filter, for a total of 40 liters per filter set.

- After a set time, perhaps two hours, the acid is drained into the waste storage tank.

- The filter is filled completely with filtered process water from the product side. The water is displaced with air into the waste storage tank. This step is repeated three times.

- The annular space between the filter and the housing is flushed with water into the waste storage tank.

- The filter is dried by flowing dry instrument air from the product side, through the filter, into the head space of the tank being vented. This process will take less than one hcur.

- The aridic wastes, about 200 liteis, are neutralized with sodium hydroxide and pumped into the tank being vented.

\subsection{Overall System Description:}

Figure 1 is a schematic of the process lines and principal instruments. The associated Table I displays the pesitions of the control valves during the phases of the operating cycle.

The entire system is mounted on a 304 SS skid with overall dimensions of 6 feet long, 3 feet wide and 6 feet high. 


\subsection{System Components:}

1.Ceramic Filters: Four membrane-coated silicon carbide filters with a nominal area of $\underline{50}$ square feet per filter

2.Filter housings: 316LSS

3.Vacuum pump - Roots or equal rated at $500 \mathrm{ACFM}$ with $6.5 \mathrm{HP}$ motor

4.Controller - AB SLC 500 PLC

5.Control system voltage - $120 \mathrm{VAC} 50 / 60 \mathrm{~Hz}$

6.Valves - all automated valves have an auto-manual selector switch for manual operation as well as open-close indicator lights on the control panel

7.Differential pressure transmitters - Rosemount series 3051CD

8.Pressure transmitters - Rosemount series $3051 \mathrm{CG}$

9. Level switches - Great Lakes Instruments model 14L

10.pH transmitter and sensor - Thornton series $200 \mathrm{pH}$

11.Recycle pump on waste tank - Goulds G\&L SST 1/2 HP TEFC

12.Nitric acid tank (316LSS) - working volume of 35 liters.

13. Caustic tank (316LSS) - working volume of 35 liters.

14.Waste tank (316LSS) - working volume of 200 liters. There is a 0.2 micron (PTFE) vent filter (1 square foot filter area). on top of this tank.

15.Caustic pump - Pulsafeeder

16. Vacuum piping - 316LSS 4 inch

17.Liquid piping.-316LSS $1 / 4$ inch

18. Water-Filters - polypropylene

4.0 Costs:

System Cost - $\$ 85,000$ estimated (to industrial standards, not to SRS standards)

Estimated Operating Costs-

Electrical power - $33,000 \mathrm{KWH}$ per year a! $\$ 0.04$ per $\mathrm{KWH}=\$ 1.320$ ner year Maintenance $-2 \%$ of $\$ 85,000 \quad-=\$ 1,700$ per year

CeraMem Corporation 


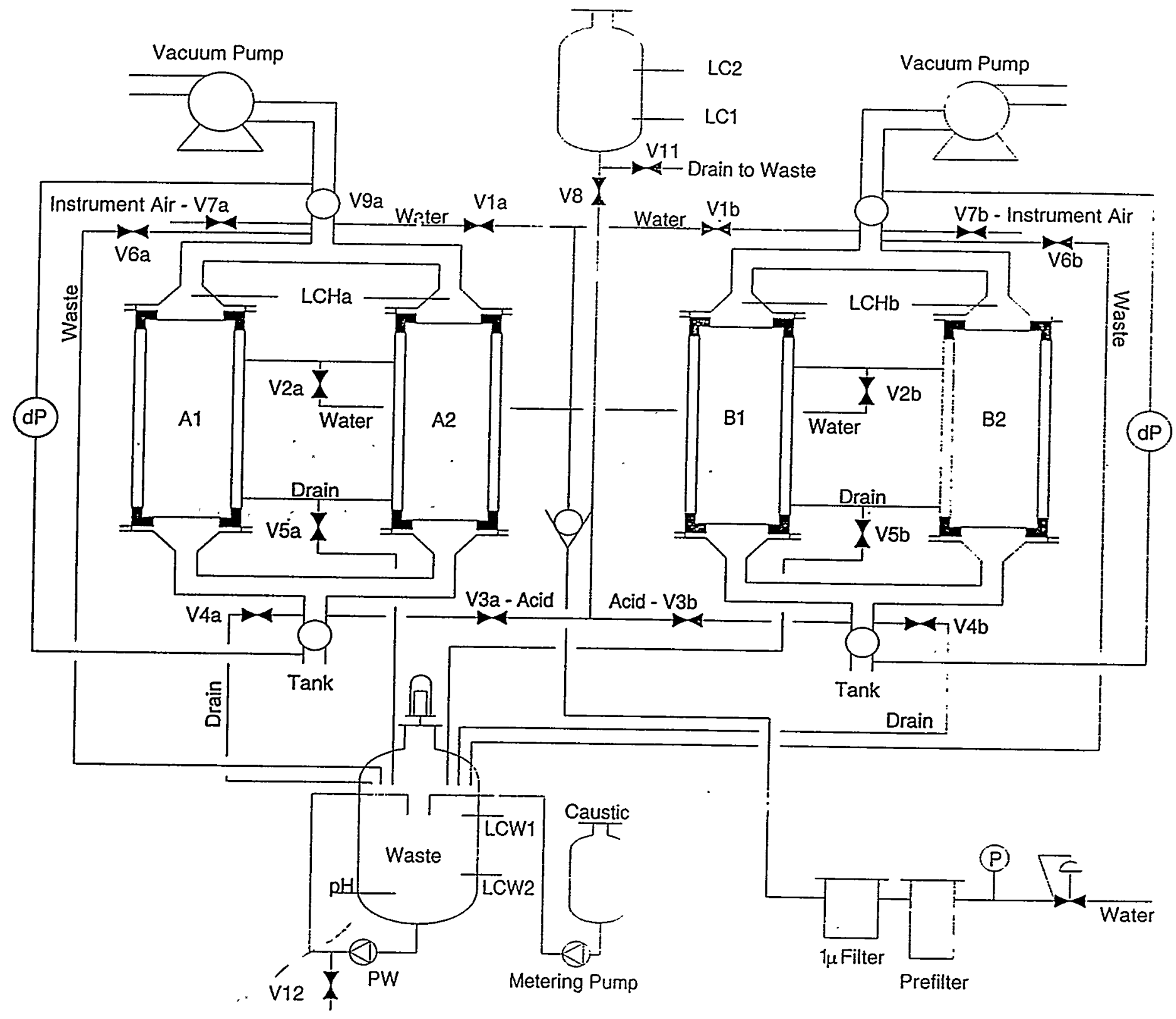

Figure 1: Flow Schematic of HEPA System 
APPENDIX 4 


\section{Robert Goldsmith}

From: William Haslebacher <WILLIAM.HASLEBACHER@fetc.doe.gov>

To: $\quad$ <goldsmith@ceramem.com>

Cc: Mary Gabriele <MARY.GABRIELE@fetc.doe.gov>

Sent: $\quad$ Friday, August 27, 1999 8:47 AM

Attach: CERCDR.WPD

Subject: Comments on Conceptual Design

Bob,

As we just discussed, here are the comments on the conceptual design for the full scale filtration system. Basically, we need more detail and some additional drawings showing the physical layout of the system. Feel free to call and discuss.

We should be faxing the letter from Mary Gabriele (with guidance on information we need on Phase II) this afternoon.

Bill Haslebacher

304-285-5435 


\section{COMMENTS ON \\ CERAMEM CORPORATION \\ ALTERNATIVE HIGH EFFICIENCY PARTICULATE FILTRATION SYSTEM \\ CONCEPTUAL DESIGN REVISION 1.0.6/23/99}

In general, the draft conceptual design is too brief and does not convey sufficient information to evaluate the viability of the full scale high efficiency, particulate, air (HEPA) filtration system concept. Specific comments are provided in reference to the statement of Task B.1.2 (bold type).

1) The contractor shall develop a conceptual design of a full-scale Regenerable HEPA Filter System (RHFS) that meets the requirements and specifications in Attachment 1 (section

2.0).

1.1) No reference is made to the contract-specified requirements and specifications. A comparison should be provided to ensure that these specifications are considered in the full scale filtration system concept.

\section{2) The conceptual design shall include, but not be limited to, materials of construction,}

2.1) Section 3.0, System Components, lists the materials of construction for piping, tanks, filter housings, and some other components.

2.2) More detail on the filter elements is needed, specifically the bonding and channel plugging materials. It is assumed that the membrane coating is proprietary and will not be reported in the conceptual design, but is compatible with the high level tank waste and cleaning solution(s).

2.3) The material of construction for the vacuum pump, valves, and any sealing materials (gaskets, etc.) should be specified. Radiation compatibility of all materials should be verified.

3) dimensions, drawings, schematics,

3.1) Overall dimensions of the equipment skid are provided.

3.2) Figure 1 is more appropriately named a conceptual process and instrumentation drawing rather than a schematic. The drawing is confusing. At a minimum, a key is needed for the abbreviations.

3.3) An artist's concept drawing and/or a series of dimensiora!, "blue ptint" style schemalics sie needed to convey the packaging of ine equipment on the skid. 
Figure 1 indicates two vacuum pumps, one for each filter set. Is this accurate or will the filter sets be manifolded together (with appropriate valves)?

4) specifications and requirements,

- 4.1) Specifications are generally listed in Section 3.0, System Components, although the skid dimensions are listed in Section 2.0, Overall System Description. Requirements are scattered throughout Section 1.0 and are not complete with respect to those specified in the contract.

5) control strategies,

5.1)The general process is described in Section 1.0, Overall Process Description. However, the description needs to be expanded. Some description of how the operator(s) executes switching between filter sets and cleaning the dirty filter set needs to be included. The selection of automated versus manual controls should be described.

5.2) In Section 1.0, Overall Process Description, the vacuum pump is described as a

- constant volume pump. The next sentence lists the discharge rate as "500 SCFM when the filters are clean." If it is a constant volume pump, the state of the filters should not affect the discharge rate within the pump's operating parameters. This also affects the criteria for switching to the other filter set, i.e., when the "vacuum pump drops to 400 SCFM." I think the apparent discrpancy results from the use of SCFM as the unit for the flow rate. This should be clarified. (The contract specifications call for 500 ACFM).

5.3) The description of the filter regeneration process in Section 1.0 describes flushing of the annular space between the filter and the housing as a separate step from flushing the filter. Is this accurate?

5.4) The description of the filter regeneration process in Siction 1.0 describes dryir. the filter with instrument air and venting this air into the head space of the tank being vented. Wouldn't this air be more appropriately routed to the manifold linking the two filter sets so that it is discharged directly to the filter set that is in line? Also, what are the pressure and flow rate of the instrument air? Would it significantly reduce the effective ventilation of the tank?

6) preliminary cost estimates, and

6.1) Preliminary capital, operating, and maintenance estimates are included, but provide no detail beyond the bottom line.

7) proposed schedule for Phase II performance.

7.1) No schedule for Phase II is included. 
8) The conceptual design shall include sufficient detail to permit a preliminary design review (including information on filter regeneration,

8.1) The regeneration strategy is described, although how it is to be executed by the operator(s) is not.

9) expected differential pressure,

9.1) The expected differential pressure across a filter set is not specified.

10) unit size and capacity,

10.1) Overall capacity of 500 SCFM is listed. The skid dimensions are listed.

11) ancillary equipment,

11.1) Section 3.0, System Components, lists the ancillary equipment.

11.2) The Roots style vacuum pump appears to be significantly undersized compared to similar pumps listed in Richard's cost estimating guide (6.5 horsepower versus 15 to 30).

11.3) The nitric acid and caustic tanks have a listed capacity of 35 liters. However, Section 1.0 states that approximately 40 liters of acid is required to clean a filter set. The storage tanks should have enough capacity for at least two cleanings.

12) etc.) as well as evaluation of the Phase II management approach and plan.

12.1) No description is provided.

Additionally, information on anticipated equipment lifetime,

13.1) No description is provided.

14) maintenance requirements,

14.1) No description of maintenance requirements is included beyond a cost estimate based on the capital cost of the filtration system. Some questions that should be addressed include: how are the acid and caustic tanks refilled? How could a filter set be replaced if necessary?

15) and expected safety concerns or risks shall be provided.

15.1) No description is provided. 
APPENDIX 5 


\title{
Facsimile
}

\author{
Leon Mir \\ 15 Hobart Road \\ Newton, MA 02159 \\ Phone: 617-244-8083 \\ Fax: 617-244-3455
}

\begin{abstract}
To: Duane Adamson $\quad$ Fax No: 8037252956
Company: Department of Energy Phone No:

Date: June 14, 1999
\end{abstract}

Message:
Duane;

Attached are the instructions for assembling the filters. Please ignore the comment on the bottom of the page about the "proprietary property"

Sincerely;

Leon Mir 
Specification: Rev. A

Title: Laboratory Scale Installation Procedure

page 1 of 5

\section{Parts List:}

1- Laboratory Scale ceramic filter module.

1- Stainless steel filter housing.

2- Stainless steel endcaps.

2- Endcap O-rings (size 209).

\section{Procedure:}

A) Remove the two 11/2" tri-clamps holding the housing assembly in the system. (See figure 1.)

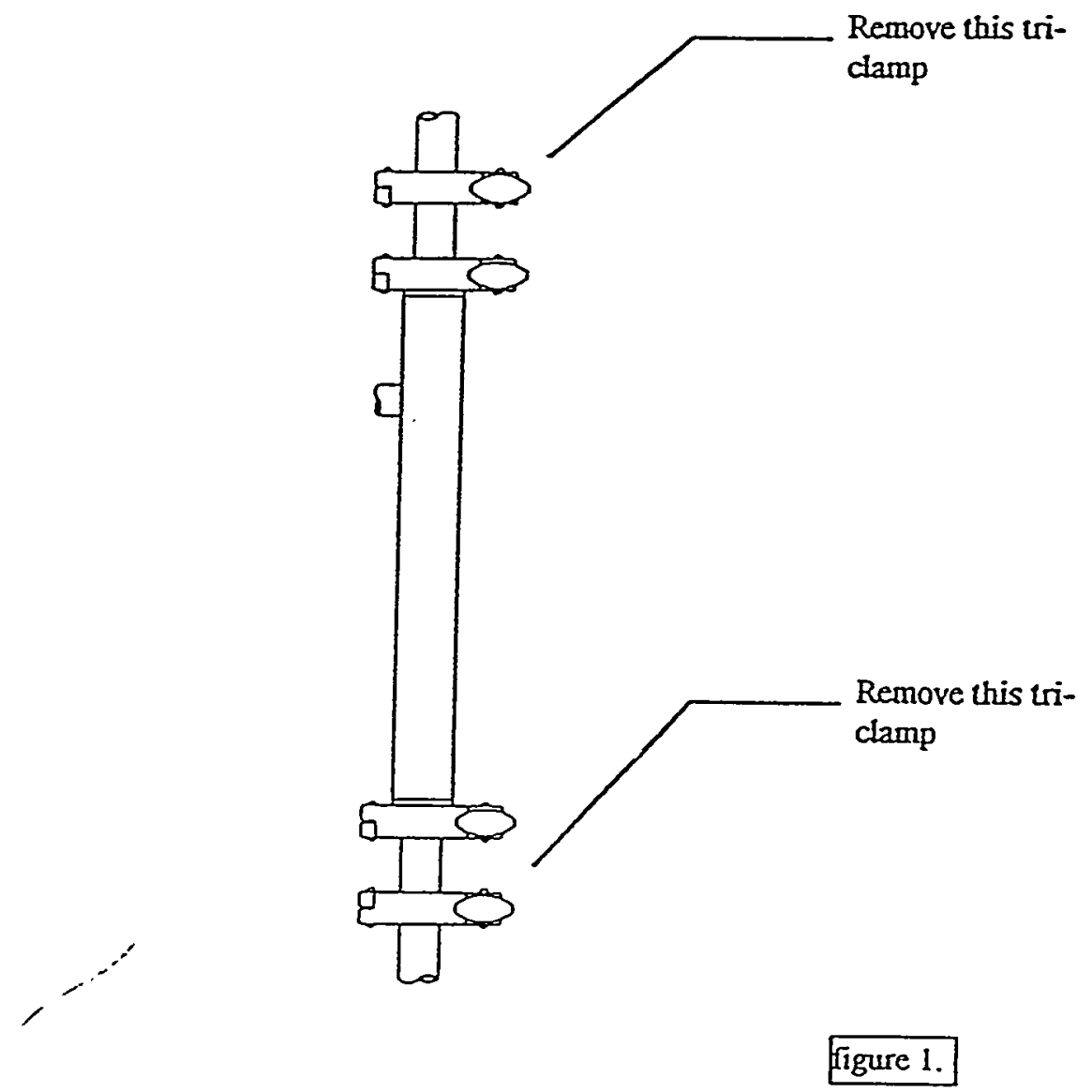

This document is the proprietary property of CeraMem Separations. 
B) Remove the endcaps from the filter housing by removing the two $11 \frac{1}{2}$ " tri-clamps. (See figure 2.)

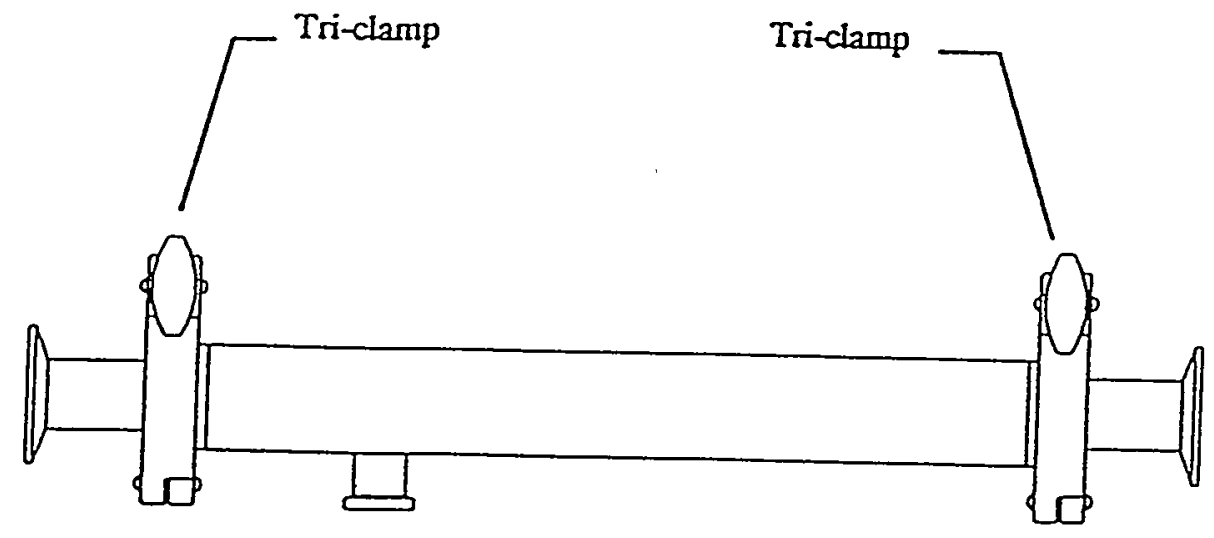

C) Place an O-ring in the O-ring groove found on the endcap. (See figure 3.)

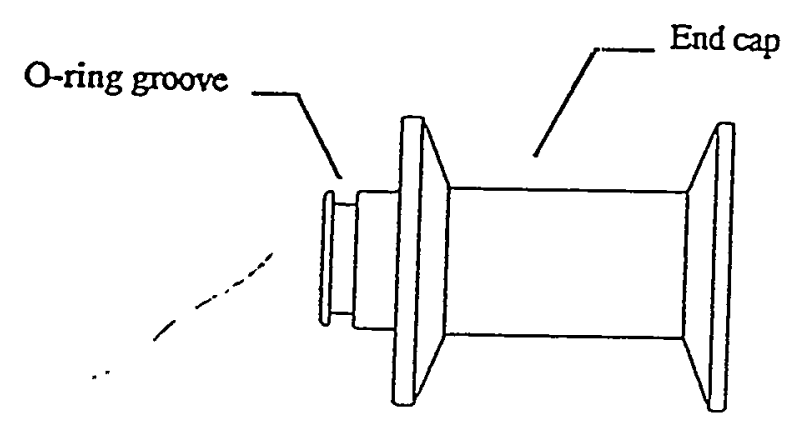

figure 3.

This document is the proprietary property of CeraMem Separations. 
D) Place a 11/2" gasket on the end cap. Gently wiggle the end ring on the filter over the nipple and $\mathrm{O}$-ring until the filter ring has bottomed out and is securely seated on the endcap. (See figure 4.)

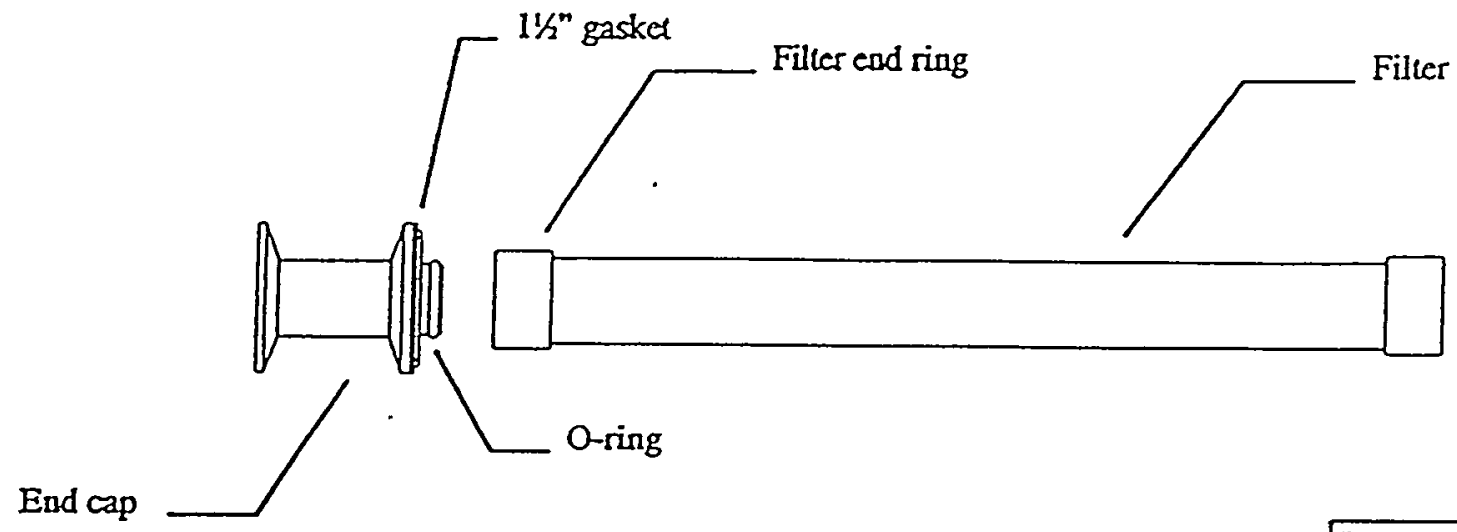

figure 4.

E) Carefully slide the filter housing over the filter and secure it to the endcap with a $11 \frac{2}{2}$ tri-clamp. (See figure 5.)

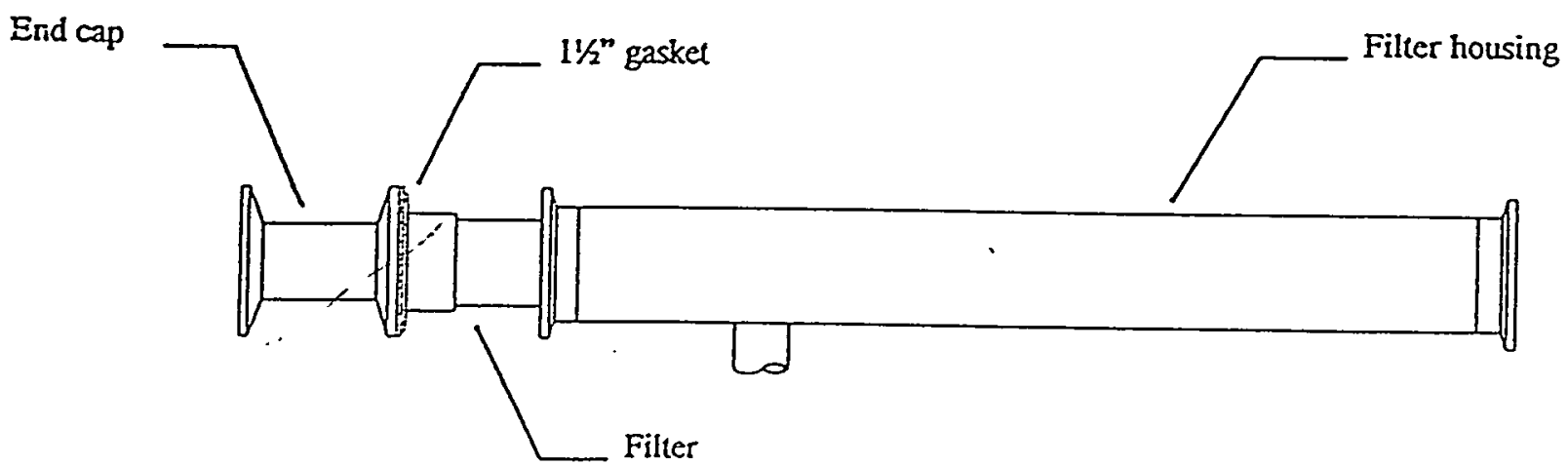

Figure 5.

This document is the proprietary property of CeraMem Separations. 
Title: Laboratory Scale Installation Procedure

F) Place an O-ring into the o-ring groove on the remaining end cap. (See figure 6.)

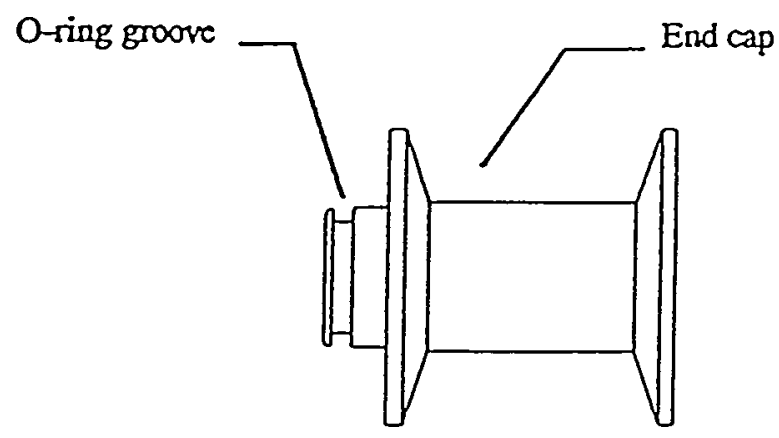

figure 6.

G) Place a 11/2 gasket on the end cap. Gently wiggle the remaining endcap into the filter and secure it with a $11 / 2$ " tri-clamp. (See figure 7.)

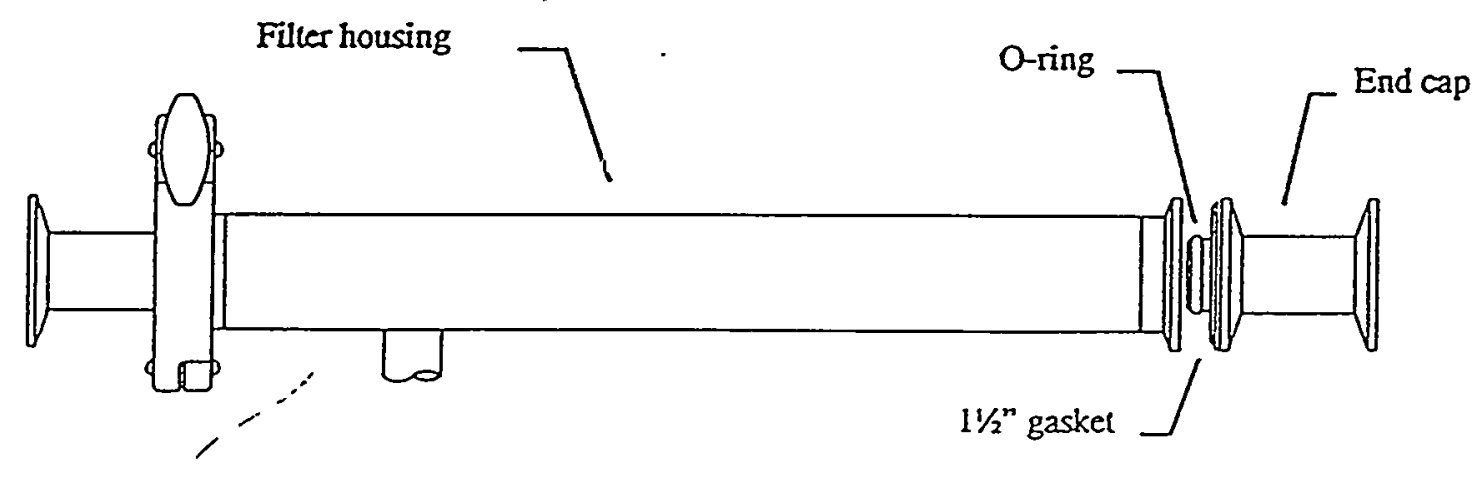

Figure 7.

This document is the proprietary property of CeraMem Separations. 
H) Filter/housing assembly is now complete. (See figure 8.)

Completed filter/housing assembly.

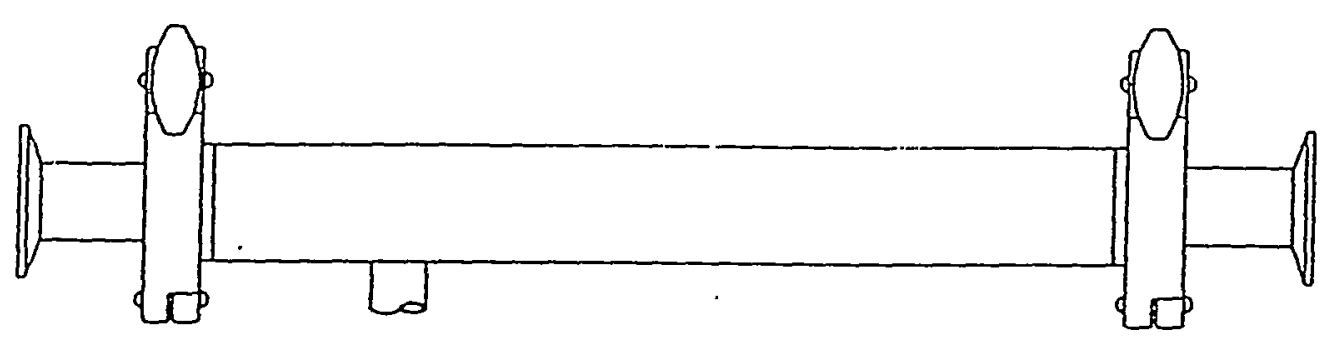

figure 8.

1) Place a $11 / 2$ " gasket on both end caps and replace completed filter/housing assembly the system. Secure the assembly with two $11 / 2$ " tri-clamp fittings. (See figure 9.)

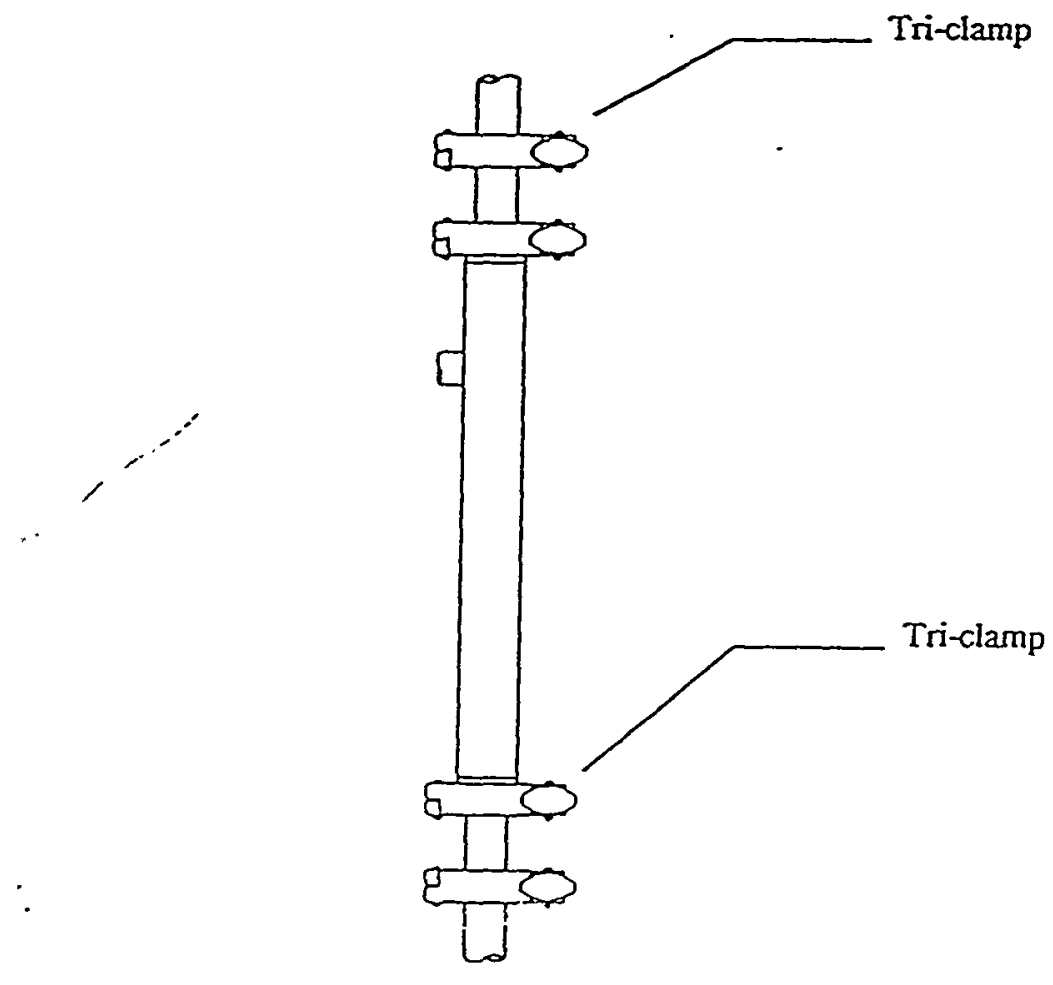

figure 9.

This document is the proprietary property of CeraMem Separations. 
APPENDIX 6 


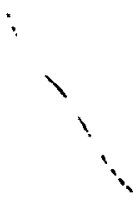

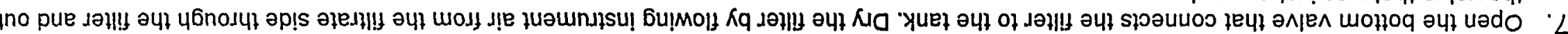
'p!oe o!!

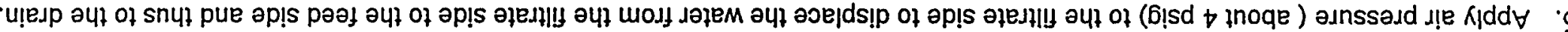

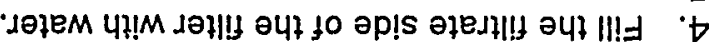

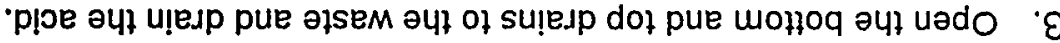

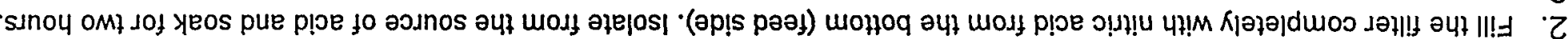

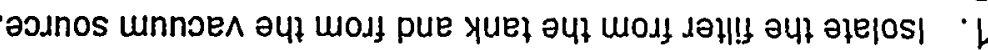

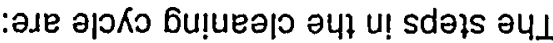

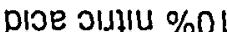

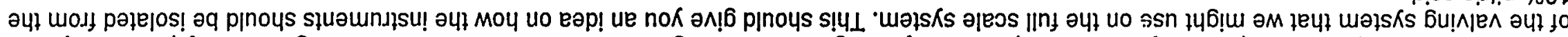

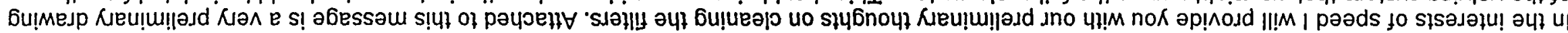

:aueng

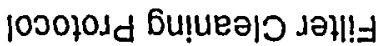

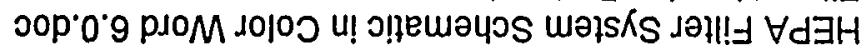
:‡วכ!qus :บวeH甘

Wd t0:t 666l 'LZ KeW 'KepsunyL

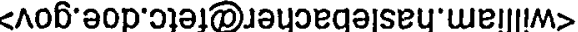

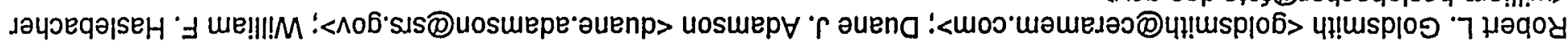
:ұUOS

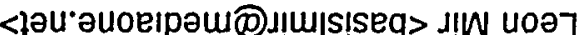


APPENDIX 7 


\section{MEMORANDUM}

To: Duane Adamson

From: Leon Mir

Subject: Suggestions for CeraMem Filter Evaluation

Date: June 15,1999

Copy:

File:

\subsection{Filtration Conditions:}

The filters have a filtration area of 0.6 square feet. At the design face velocity of 10 feet per minute the inlet flow rate should be about 6 ACFM.

The corresponding pressure drop should be less than 50 inches of water.

\subsection{Regeneration Sequence:}

The sequence of regeneration steps; acid soak, water rinse and drying should be carried out as described in the proposed regeneration procedure of the full scale system.

\subsection{Specification:}

3.1 The filter housing should be completely filled with nitric acid; about $300 \mathrm{cc}$. of acid will be needed.

3.2 The filter housing should be completely filled with water in carrying our each rinse.

3.3 It is important to dry the filter completely after the water rinses in order that no filter pores be blocked with water and thus unavailable for air filtration. This should be accomplished by purging the water with 4 psig, dry, instrument air. This drying process should take less than one hour. It can however be monitored with a wet bulb thermometer to determine if a shorter period of time is adequate. 
APPENDIX 8

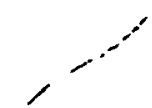

